\title{
The market for scientific lemons, and the marketization of science ${ }^{\&}$
}

\author{
(El mercado de los limones cientificos y la mercantilización de la ciencia)
}

\author{
Jesús ZAMORA BoNILLA* \\ UNED, España
}

\begin{abstract}
Scientific research is based on the division of cognitive labour: every scientist has to trust that other colleagues have checked whether the items that are taken as knowledge, and she cannot check by herself, are reliable enough. I apply ideas from the field known as 'information economics' (the study of economic interactions where some agents are better informed than others) to analyse the scientists' incentives to produce items of knowledge of an 'adequate' quality, under the assumption that a big part of what one observes in her empirical research is not available for the readers of the paper. I also discuss some criticisms to this 'marketization' of science studies.
\end{abstract}

KEYWORDS: Division of cognitive labour; trust; rational choice; economics of information; information asymmetry; scientific norms; scientific institutions; commodification.

RESUMEN: La investigación cientifica se basa en la división del trabajo cognitivo: todo científico ha de confiar en que otros colegas hayan comprobado que los items que son considerados como conocimiento y que no pueden ser comprobados por él mismo son suficientemente fiables. Aplico aqui ideas del campo conocido como «economía de la información» (el estudio de las interacciones económicas en las que algunos agentes están mejor informados que otros) para analizar los incentivos de los cientificos para producir items de conocimiento de una calidad «adecuada», bajo el supuesto de que una gran parte lo que observan en su investigación empirica no está disponible para los lectores de un artículo. También discuto algunas críticas a la «mercantilización» de los estudios sobre la ciencia.

PALABRAS CLAVE: División del trabajo cognitivo; confianza; elección racional; economía de la información; asimetría de la información; normas científicas; instituciones cientificas; mercantilización.

\& This article has benefited from Spanish Government research project FFI2017-89639-P, "Mechanisms in the sciences: from the biological to the social".

* Correspondence to: Jesús Zamora Bonilla. Departamento de Lógica, Historia y Filosofía de la Ciencia. Facultad de Filosofía. UNED. Senda del Rey, 7. 28040 Madrid. Spain - jpzb@fsof.uned.es - http://orcid.org/0000-0003-0185-9768

How to cite: Zamora Bonilla, Jesús. (2019). «The market for scientific lemons, and the marketization of science»; Theoria. An International Journal for Theory, History and Foundations of Science, 34(1), 133-145. (https://doi.org/10.1387/theoria.19508).

Received: 20 March, 2017; Final version: 17 September, 2018.

ISSN 0495-4548 - eISSN 2171-679X / (C) 2019 UPV/EHU 


\section{The division of cognitive labour and the problem of trust in science}

Science, as most activities in complex societies, is based on the division of labour, in particular, on the division of cognitive labour. ${ }^{1}$ No individual scientist can check by herself most of the knowledge she 'has' of her field (not to mention knowledge about neighbouring fields), but needs just to trust what is taken as 'knowledge' by her colleagues as actually known. Of course, every bit of 'knowledge' can turn out being false, and some researches may end establishing that some bit of past 'knowledge' has to be substituted for a new, different piece of it. But usually there is the need of accepting by default what the relevant community of experts has adopted as 'correct information'. Every scientist belongs to at least one of these 'communities of experts', and this makes her responsible of doing her part of the task in assuring the rest of the scientists out of those small groups, as well as the rest of society, that some specific items of information are 'reliable knowledge'.

The question is, what warrants that every scientist complies with this responsibility? Casual conversation with academics of any branch of science gives the impression that they tend to think that individual honesty is all that is required, and that, actually, science is trustful mainly thanks to it. Even exposing them to an analysis or reasoning as the one I shall offer in section 2, it is received, at times, as a kind of insult... this has been at least my experience after two decades working on the 'economics of scientific knowledge'. This fear to 'selfishness' is so intense, that some specialists in the social analysis of science worry that just performing that analysis with the help of rational choice theory (RCT) as a basic intellectual tool (e.g., studying science 'as if it were a market') would have the risk of 'contaminating' the purity of science and contributing to its 'marketization'; I shall examine some of these criticisms in the last part of my paper. ${ }^{2}$ On the other hand, recurrent complaints about the extent of fraud and other misconducts in some branches of science (E.g., Ioannidis 2005; Fanelli 2009), or about the 'replication' or 'reproducibility crisis' (E.g., Nature 2016), or about the excess of publications (E.g., Siebert et al. 2015), or about the dangers of an excessive privatisation of research (E.g., Laughlin 2008), make it clear that there is the feeling that trust in science must be guaranteed by some other procedures than naive resorting to individual rectitude, for this rectitude flourishes more and better in some social, cultural or institutional environments than in others. Lastly, we should mention that 'science studies' in the last fifty years have established beyond any reasonable doubt that scientific knowledge is often, if not always, the result of some kind of 'negotiation', or at least some kind of 'social construction', and, even if we prefer not to take it in a relativistic, or 'too constructionist' fashion, this entails that the public outcome of scientific research is not something that can be algorithmically derived from totally objective data, but something that is always open to some degree of interpretation, and that different scientists may have reasons to prefer different interpretations and, hence, reasons to consider some possible outcomes as 'better' or 'worse'. 3

1 See Kitcher (1990) for a classic statement, and Weisberg (2017) for a recent summary.

2 For a general survey of the application of economic theoretic tools to the study of science in its epistemic aspects, see Zamora Bonilla (2011a).

3 See Chang (2004) for a clear, not relativist case. 
In summary, 'proper' scientific conduct is essential to the credibility of scientific knowledge, but why scientists actually behave in such a 'proper' way, and how they end defining and implementing that way, is something that cannot be taken for granted but that needs explanation. My goal in this short paper, however, is not to offer a full fledged theory explaining 'why science works', but to propose a couple of insights that may help us advance in the direction I think is most promissory. I will make use of RCT (after all, is it not a nice minimal default assumption that scientists are rational agents?), and in particular of one of its most (theoretically and empirically) successful applications in the social sciences: the tool known as the economics of information (EI) (See Birchler and Bütler 2007). Contrarily to the standard microeconomic models applied to cases like perfect competition or perfect monopoly, EI assumes that different agents may have different information sets (mainly because information is not usually free, but more or less costly to acquire and to master), and it explores the consequences this asymmetry has under different contexts or institutional arrangement (i.e., 'markets'). EI is particularly important in any attempt to apply RCT outside its classical field of economics, because it makes it explicit that analysing a social situation in terms of 'a market' does not entails that everything in that social context works automatically towards an optimal outcome 'as if lead by an invisible hand' thanks to the agents' selfishness (to use the famous Adam Smith's metaphor). Rather on the contrary: some 'markets' can work indeed quite badly, and this can justify some kind of 'public intervention', even if this consists in a group of agents collectively deciding to modify the institutional arrangement that is causing their problems. So, an economics-of-information analysis of science is not necessarily a 'pro-market' approach in any problematic sense of the 'market' metaphor.

The rest of the paper is organised as follows. Section 2 presents a toy model of the 'market for scientific papers', inspired in one of the founding pieces of the EI literature: George Akerlof s 'The Market for Lemons' (1970). The model is not assumed to offer a detailed, nor even an empirically adequate view of how the production of scientific papers actually goes on. Instead, as models usually do in social sciences, its goal is to help us 'isolate' (cf., e.g,. Mäki 2009) some 'essential' factors that may play an important role in the relevant processes, even if in the actual world those factors are to some extent 'neutralised' in order to avoid its possible pernicious consequences, or work in conjunction with other factors that help disguise the formers' distinctive effects. Section 3 will take advantage of some of the conclusions of the previous one, and will turn to a more general discussion about the possible connections between a market-like analysis of the production of scientific knowledge, on the one hand, and the 'marketization' of science, on the other. In order not to make the discussion too lengthy, I shall concentrate in discussing one recent and scrupulous criticism of both types of 'marketization', Ylva Hasselberg's paper "Demand or discretion? The market model applied to science and its core values and institutions" (2012), though I shall also refer of course to some other authors.

\section{The market for 'scientific lemons'.}

Akerlof s 'Market for Lemons' presents an idealised model of the market for used cars, in which sellers know the real quality of each car, but buyers are not able to distinguish both 
types of cars before buying them and using them for a time. The price buyers are willing to pay for good used cars ('peaches') is higher than the one they would pay for bad ones ('lemons'), but, being not capable of noticing the difference between both types of cars in the lot, the clients would be willing to pay a price for every car which is equal to the weighted average of what they would pay for good and bad ones (the weights being equal to the known or estimated proportion of each kind). This price would be not accepted by sellers for good cars, for it is lower that these cars' 'real' value, and hence, sellers will have an incentive to sell only bad cars, 'lemons'. Of course, clients, knowing this, will only offer their price for bad cars. The asymmetry of information between buyers and sellers (their different degree of knowledge about the real quality of each single car) will have created, in this way, what in EI literature is called an 'adverse selection' problem: the market works in such a way that it only 'selects' the bad items.

Akerlof s paper didn't claim that the market for used cars actually worked in the way his model depicted. Even, the concept of 'used cars' (or 'lemons') is employed in the paper not as literally referring to those specific goods, but as an illustration of any type of exchange in which the parts happen to have different information about what is exchanged. Akerlof explicitly mentions the labour markets, insurance markets, as well as underdeveloped economies and 'the cost of dishonesty', as other examples about which his theory could offer some useful insight. In a sense, what I shall try to do in this section is to include the process of creation of a scientific paper in the set of possible applications of Akerlof s scheme (if not strictly of his model, since in the case I shall examine there are no 'prices').

The information asymmetry in the 'market for lemons' is about the intrinsic quality of a material good: sellers know the cars better than buyers. Does something similar occur in the case of science? I think it is reasonable to claim that, because of the 'division of cognitive labour' we have mentioned at the beginning, the author of a scientific paper unavoidable knows much more than her typical reader about the work that has been carried out in order to elaborate the text (let's consider, e.g., one paper that reports a laboratory experiment or field observation, or that uses these as arguments in favour of a conjecture, theory, etc.). If the mythical, naive positivist view of 'the scientific method' were right, there would be an algorithmic procedure to 'translate' the results of the experiments/observations into a text, so that the 'final' paper would simply become a transparent description of 'the facts'. But every working scientist, as well as every historian, philosopher or sociologist of science worth his salt, knows that in the real world things are much more complicated. The paper necessarily offers just a selection, or summary, or interpretation (or all of it), of the empirical results and the steps that have been taken. The claim of the paper (either a 'description' of the results, or a conjecture supported by them) is one, but in principle it could have been different if a different interpretation or use of the results had been made. Papers that have been co-authored (as most of them are in experimental science) show still more clearly that this 'space of possibilities' exists, because in this case co-authors 'negotiate' the specific content and claims that will be included in the final text (cf. Knorr-Cetina 1981). And in many cases, 'negotiations' between authors, referees, and editors can also be understood as attempts to make more congenial the content of the paper with standard ideas or practices within the discipline, or to disclose a little bit more of what the author has kept 'concealed' in the article's first versions (See, e.g., Gosden 2003; García et al. 
2017).The process of writing of a scientific paper partly consists, hence, in choosing one text from a set of possible texts, all of these more or less 'justifiable' by the empirical results obtained by the authors. The relevant information asymmetry here lies in the fact that, in principle, the authors know the whole set of possibilities (what they 'could have claimed' given their results), but the readers only know just one of the possibilities, the one that has been chosen by the authors; i.e., the typical reader basically ignores what other papers the authors could have written using the same results. I insist: the 'results' themselves are hidden for the readers, for it is only the specific description/interpretation of the results what they get from the published paper. Naturally, one of the basic points of science is that these results must be reproducible, but 'replication' necessarily consists, at most, in producing a new, different set of results, whose description/interpretation will be assessed in order to see whether it can be considered as coherent or incoherent with the original published report.

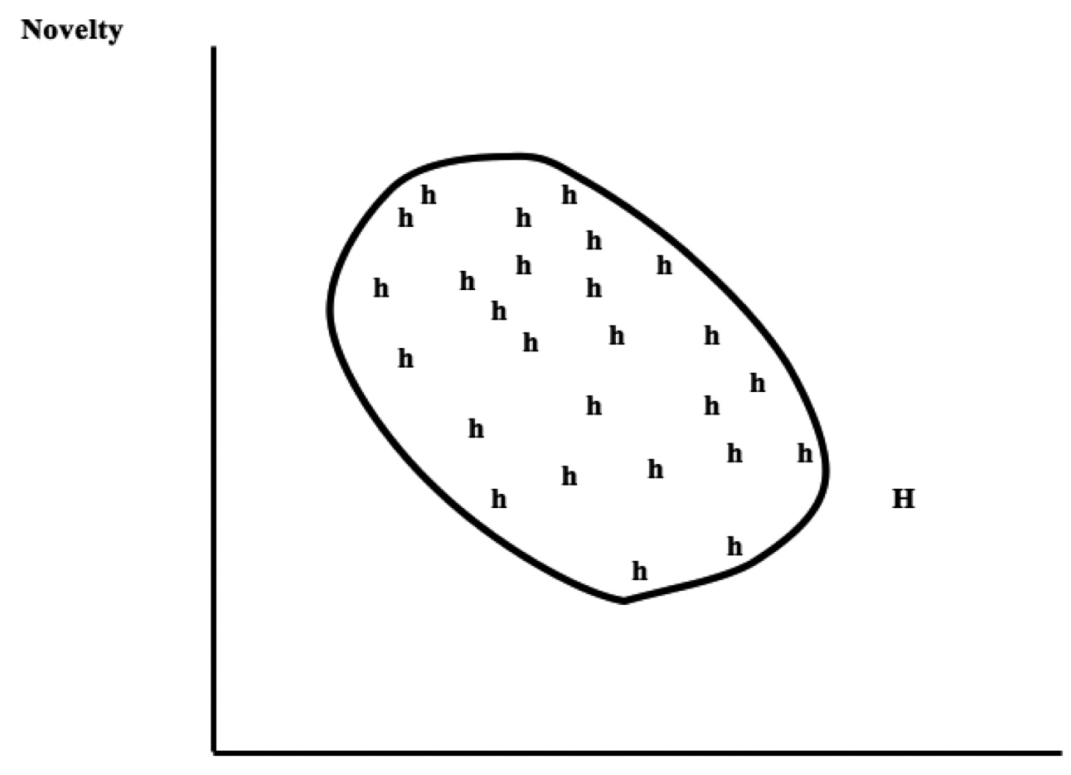

Plausibility

Figure 1

RCT can be employed at this point to illuminate the scientist's (or author's) decision of choosing one particular way of expressing her results. The cloud of points $H$ in fig. 1 represents the possible articles (or 'hypotheses') she might write on the basis of those same results. Our first question is, what different properties or qualities each option has, so that some of them are 'better' from the point of view of our scientist? In order to keep the complexity of my argument at a minimal level, I will discuss only two of those qualities: the degree in which the scientist thinks one possible interpretation will resist future criticisms, and the 
degree in which she thinks the interpretation is original or innovative. I shall call these two properties 'plausibility' and 'novelty' respectively; they are measured respectively by the horizontal and vertical axes. I will also make the simplifying assumption that every member of the relevant scientific community, i.e., all the potential readers of the paper our scientist is to write, would agree with her on the values of these two qualities for each possible interpretation if it were the chosen one. A couple of variables that may work as proxies for plausibility and novelty are the posterior and prior probabilities of the claim made in the paper, i.e., $p\left(h / E_{b} \& B\right)$ and $p(h / B)$, where $h \in H$ is the claim, $E_{b}$ is the offered description of the empirical results if $h$ is chosen, and $B$ is all relevant background knowledge shared by the scientific community.

One important feature of the set $H$ is that its 'frontier' in the upper right side of the graph will very likely have a negative slope. This simply means that, though the author may choose interpretations with a higher or lower value of each two epistemic variables, at some point it must be the case that improvements in one of the qualities (e.g., finding out a more plausible claim) can only be attained at the cost of decreasing the other quality (i.e., making it less innovative). The author might want to be capable of devising a paper that were better in both regards, but her results do not allow such an utopian accomplishment.

A second question is, how these values affect the author's optimal choice? This will depend on the expected decision that readers will make about the paper. Simplifying again a lot, when one possible interpretation is made public, readers have two possible reactions: either accepting it or rejecting it. If the paper's claim is rejected, the author gets a utility of 0 . If it is accepted, it is reasonable to assume that the author's utility basically depends on how 'important' the claim seems, and this will directly depend on its degree of novelty. Hence, a preliminary question for the author is to make a distinction between those $h$ 's that will be accepted and those that will not. Assuming (again with a great dose of idealisation and simplification) that she shares with all her colleagues the disciplinary criteria about when are papers 'good enough' to become acceptable, the author will directly know the answer to this question just by being a member of her discipline. It seems reasonable to assume that these criteria depend on the two epistemic factors we have mentioned: plausibility and novelty; 'good papers' are those that have a sufficiently high degree of both qualities, with some room for higher degrees of one compensating, to some extent, lower degrees of the other. This entails that the epistemic indifference curves for the readers will be decreasing and convex, ${ }^{4}$ and representing a higher utility level as they are further away from the origin of the graph, as depicted in fig. 2. This figure also shows a thicker curve $\left(U_{L}\right)$ that is defined by being the lowest utility level the discipline has to get from one paper for it to become 'acceptable'; hence, this represents the acceptability threshold: claims worse than that are rejected, and claims above the line are accepted.

4 Convexity means that a linear combination of two points $x, y$ in the graph which are equally preferred (i.e., a point $z$ lying on the straight line joining $x$ and $y$ ) is necessarily preferred to each of them, i.e., $U(z)>U(x)=U(y)$. 


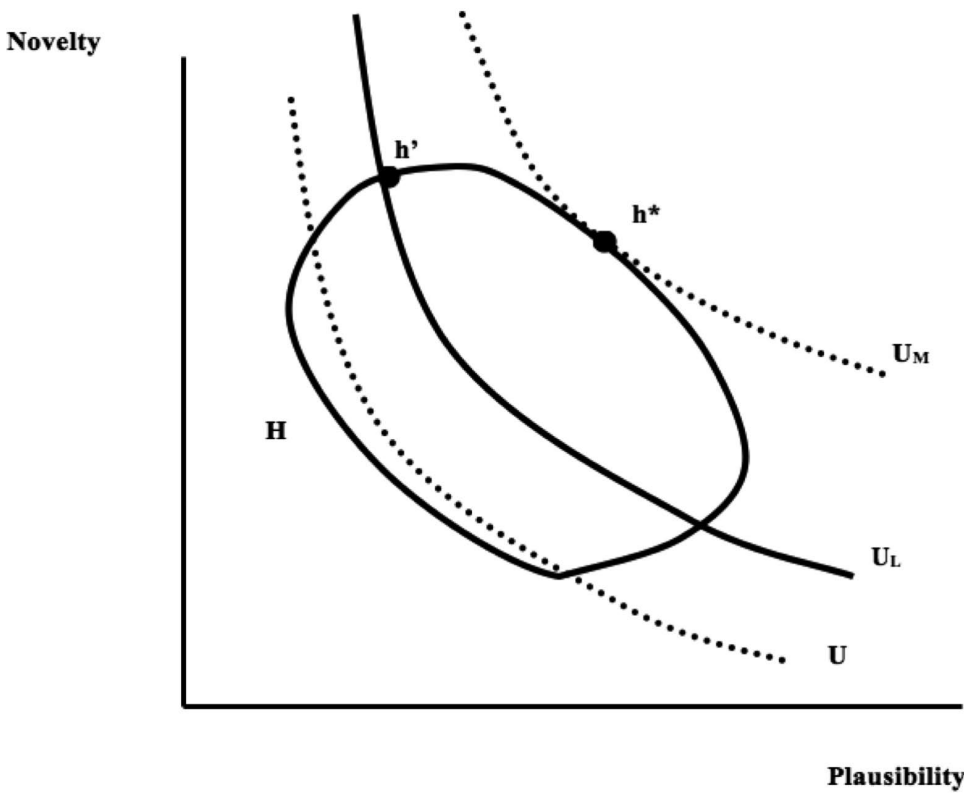

Figure 2

Knowing all this, our author's choice is already determined: the best choice for her is to select the interpretation that is both over $U_{L}$ and that has the maximum possible novelty, i.e., the claim $b^{\prime}$ of fig. 2 . However, as it is also clear from the figure, it can easily be the case that $b^{\prime}$ is not the paper that readers would have preferred if they had known all the possibilities, for their best choice (in the case depicted in the figure) would have been $b^{*}$, i.e., the element of $H$ which lies in their highest possible utility curve, $U_{M}$. Stated differently: the existence of asymmetric information entails that the author's optimum may not coincide with the community's optimum. Under the idealised and simplified conditions depicted in my argument, the members of a scientific community will tend to produce papers that are not epistemically optimal from the point of view of their own epistemic criteria.

As it was the case with Akerlof s paper, my analysis does not attempt to proof that this is an empirically accurate description of the process of writing and accepting scientific papers. It only identifies a tension that exists between the different interests of scientists depending on whether they are acting in their role of authors or in the role of readers. The main insight that can be gained thanks to looking at the creation of scientific knowledge from this viewpoint is that some scientific institutions or practices can be seen as attempts to resolve this tension (i.e., to persuade authors to select an interpretation of their results which is closer to the community's optimum), or, instead, as factors that can end giving authors more freedom to select papers that are epistemically 'too bad'. In the positive side we can mention institutions like peer review, that tends to downgrade the authors' claims and to demand stronger justification for them, (Gosden 2003) the existence of different journals of different average quality, i.e., with different $U_{L}$ thresholds in the sense of fig. 2, etc. In the negative side we find some of the problems mentioned in section 1: lack of incentives to 
replicate findings, excessive pressure for publishing, etc. In particular, a higher probability that the results are not externally checked tends to enlarge the set $H$ of possible interpretations of the empirical results in the direction of the vertical axis, namely, including strong claims that are apparently but not really 'justified' by the actual results.

\section{The marketization of science and the 'marketization' of science studies}

One can criticise arguments and models like the one I have offered in the past section on basically two different types of grounds. In the first place, one can argue that this or other similar model is too simple, or too idealised, or not simple enough, or that it fails to include some relevant variables or some type of interactions between agents, or that the type of 'market' or 'rules' assumed in the model are very far from how the 'market for scientific papers' really words. These criticisms would not dispute that it can be reasonable to analyse the decisions of scientists, as well as the outcomes of these decisions, in terms of rational choice theory or, more precisely, with game-theoretic tools; they only would suggest that a particular market-like analysis of scientific research could certainly be improved in many ways. But in the second place, one can make an overall amendment to the idea of studying the process of scientific research in a similar way as theoretical economists study markets and other social institutions. One reason put at times to justify this general criticism is the claim that the 'new economics of science' or 'economics of scientific knowledge' (as this type of analysis are often known) (Cf., e.g., Ballandonne 2012; Fernández Pinto 2016) is simply an ideological henchman of the general political trend towards the privatisation of public services in general and of scientific research in particular, a neoliberal rhetorical strategy to persuade scientists, politicians and the public that science can be controlled through economic handles as almost anything else within society. Historian of economics Philip Mirowski is one particularly clear voice in criticising what he sees as

a fundamental fallacy: that "science" can and should be subject to the very same analytical prac-
tices (what they engagingly call tools) that they have applied to any other commodity or situation
- in other words, there is nothing particularly special about science (... Instead,) scientific research
is above all a process that has to remain open to the serendipitous, the unexpected, the incongru-
ous, and the unanticipated. (Mirowski 2011,391)

There are two serious mistakes in a criticism like this one. First, an economic or game-theoretic analysis of the creation of scientific knowledge does not necessarily lead to a 'neoliberal' economics of science or science policy. Rather on the contrary, it may lead (as it has been precisely the case in the model I have offered in the past section) to the identification of 'market failures' whose solution demands some type of public or collective management, perhaps because of fundamental uncertainties of the kind suggested by Mirowski; or even, it may be totally separate from questions about science policy properly understood (speaking for myself, I can say that my main use of economic tools in 'science studies' has been to discuss some epistemological questions, not political or managerial ones). Second, applying the formal apparatus of game-theory to some field does not amount to assume that the field has 'nothing peculiarly special'; it is, instead, the attempt to see 
whether and how the special aspects of the field can be illuminated by considering them from the point of view of game-theory. Of course, this does not entail that the insights gained from the use of this formal tool are so powerful and accurate that any other type of analysis can be dispensed with. Game-theory, as any other social science paradigm, has its own methodological and substantial limitations, and any other different kind of study that complements its multiple gaps or remedy its unavoidable shortcomings will naturally be welcome.

But the paper I would like to concentrate on, since I think it is one of the clearest examples of the type of criticisms mentioned above, is Ylva Hasselberg's "Demand or discretion? The market model applied to science and its core values and institutions" (2012). Hasselberg laments that substituting 'the economic logic of the market' for what she calls 'scientific judgment-driven rationality', i.e., considering scientists as neoclassical agents, would lead to loose the fundamental characteristic of scientists' judgment, which is not algorithmic or deductive, but based on qualitative, context-dependent reasons, and governed by discretion (what she defines as taking into account "what is perceived to be good, correct, or even beautiful" p. 37), always according to professional, intersubjective values and norms. It is not only the way scientists make decisions what would change were they to be 'neoclassical agents', but also their own goals, for economic theory depicts individuals as pursuing just their own private benefit or self-interest, instead of 'collective cultural values' such as truth, for example. This could lead, according to Hasselberg, to the commodification of science:

Commodification means (1) that the relationships that surround a commodity are transformed into market relationships and (2) that exchange value or market value will take priority to all other kinds of value. Work that does not contribute to market value is meaningless. Knowledge that cannot be transformed into a marketable product with a market value is also meaningless. (p. 40)

This 'commodification' would happen because, if economic rationality takes the place of scientific judgment, science would be governed by a type of 'recognition capitalism' as the one classically depicted by French sociologists like Bourdieu, Callon or Latour (See, e.g., Latour 1987). Under such a regime, the production of scientific papers would just respond to the demand and supply forces determined by the search for recognition and by the costs of the different strategies. In such a market, the scientist

wants to exchange as little knowledge as possible for as much cultural and economic capital [i.e., recognition and research resources] as possible (...) Demand replaces discretion as an ulterior motive for producing knowledge. Knowledge that is not in demand will not be produced. It also means that there is no driving force towards procuring as much knowledge as possible (...) The scientist on the market does not care for knowledge in itself. Values as well as emotions are external to the market model, and if they come into the picture they possibly create disturbances or market imperfections. (p. 44)

Furthermore,

texts will tend to lose their use value and retain only their exchange value. The main point is that reading becomes instrumental and shallow (...) The knowledge base necessary for intersubjectivity will be diminished (...) The supply-demand mechanism will tend to downplay discretionary 
decision making and shift focus from the text as a means of communicating the result to the text as a commodity on a market of publication (...) In the neoclassical model of science, only scientific development that leads to a text that can be marketed is desirable, assessable, or even possible to discover. Ideas and thoughts, no matter how brilliant they are, are not marketable. (p. 49)

In summary, if science became a market, the 'traditional' cycle of production of knowledge, that according to Hasselberg was 'article-recognition-article' (i.e., recognition as a means to the production of knowledge), would be replaced by a 'capitalist' cycle of the 'recognitionarticle-recognition' type (i.e., one in which knowledge is produced just as a means to attain recognition), where knowledge that is valuable for its own epistemic merits would no longer be pursued, nor even recognised as valuable.

To these claims, I think we can respond with the following arguments. In the first place, we have to make a clear and emphatic distinction between the theoretical instruments of the analysis of science, on the one hand, and the real psychological or institutional features of the people and groups involved in real scientific practice. Understanding science 'as if it were a market' needs not change real science more than what understanding the reproduction of ants 'as if it were a market' would change the sexual behaviour of ants. The case is clearer if our object of study is not contemporary science but some historical episode. Would Hasselberg and the other critics of the economics of scientific knowledge really believe that absolutely no insight can be gained about, say, the history of the Scientific Revolution by viewing its protagonists as engaged in some types of 'games' or 'epistemic markets'? Furthermore, even if being exposed to some rational-choice analysis of their own practice would lead some real scientists to change to some extent their values and strategies, it is by no means clear that this change would necessarily be in the direction towards a "commodification' of science and towards loosing the good-old-fashion scientific values praised by Hasselberg (and, if it is, what if scientists know better?).

In the second place, it is a fundamental miscomprehension of rational choice theoretic analysis to assume that it is based on a selfish calculation of egoistic preferences instead as on cultural norms or something like that. Rationality, in the sense of 'utility maximisation', only means that we make the assumption that the agents behave as if they were trying to maximally satisfy a coherent system of preferences, no matter what these preferences are: they can be 'selfish', or they can be as 'communitarian' or 'institutional' as we want. ${ }^{5}$ If real scientists have an interest in the pursuit of truth and understanding, our goal as students of science would be to determine the real strength of this interest in their overall system of preferences and motivations, not to fool ourselves by imagining that they only pursue 'noble' goals. Neither have we to interpret rational choice theory as assuming that the agents' 'decision process' reduces to a mathematical optimisation calculus; the theory is in itself agnostic about the psychological mechanisms that lead agents to their decisions,

5 Cf., Sen (1991). A referee of a previous version of this paper justly complied that I had only considered 'rationality' in the sense of rational choice theory, and that other views of rationality are common in the social sciences. This is true, of course, but it is just an unavoidable consequence of my paper's main goal: to present a rational choice model of the production of scientific paper, and to defend its methodology from some criticisms that I consider not appropriate, like Mirowski's and Hasselberg's. For any reader interested in the more general question of the different senses of rationality in the social sciences, I have discussed it in more detail the topic in Zamora Bonilla (2011b). 
and these mechanisms can be as 'discretionary' or 'judgmental' as we please; the only assumption rational choice theory makes (and very probably a very simplified and only approximate one) is that the outcome of every decision will be 'optimal' from the point of view of the agent's preferences and values, i.e., that when they discover that they could do something that leads to a better result, they do it (though optimality not necessarily arises at the collective level if there are 'collective action problems', i.e., if the 'games' do not lead to a socially efficient outcome; it can also be that individuals fail to find the optimal strategy due to rationality limits, but this can also be studied by means of 'economic' models) (see, e.g., Mallard 2015).

In the third place, it is also a mistake to assume that an economic analysis leaves necessarily outside anything that has to do with 'social norms'. Rather on the contrary, rational choice and game-theoretic analysis can serve to illuminate the emergence of some norms, and to clarify the virtues and defects of real or possible rules. Furthermore, usually an economic analysis cannot even start in a 'normative vacuum', for it always presupposes some normative frame or another (for example, property rights, government power, etc.). In particular, economics of information is one branch of economics specifically devoted to explain the emergence and working of some institutions, and even to design them (see, e.g., Gintis 2009).

In the fourth place, economic analysis does not always assume that social institutions work 'as a market'. Rather on the contrary, it can also try to explain why in some cases economic agents prefer to carry out certain activities out of the market. One classical example of this is Ronald Coase's theory of the firm (Coase 1937), since the capitalist company is typically an institution that competes within a market but that does not internally work according to market rules, but according to bureaucratic organisation and hierarchical values. These may not be the same values typical of science, of course, but there is nothing that prevents an economic-type explanation of why scientific research follows very different procedures and norms than the ones we find in the markets for typical economic goods.

Fifth: even if epistemic values like 'truth' or 'knowledge', on the one hand, and 'private' values like 'recognition' have to be included as different variables in the scientists' utility function, this does not necessarily mean that the latter are totally independent from the former. After all, recognition is not 'mere recognition', but intrinsically consists in 'recognition for something'. Even a totally 'cynical' researcher, in the sense that she didn't care at all about the epistemic value of her discoveries, would try to get really important results if their colleagues attribute a higher level of recognition to this type of findings. And a group of persons who were totally indifferent to the value of knowledge would probably find many other activities much more appealing and gratifying than boring scientific research, like people who don't love physical exercise and the glory of being champion would hardly become athletes. The toy agents depicted in models like the one I have presented in the past section are, in this sense, not so different from the idea Hasselberg has of real scientists.

Sixth, and last: even if you are afraid of the 'commodification' of science, applying 'market' ideas may turn out being a better strategy for you than just mourning for the loss of the good old days when science was a romantic enterprise. The reason is that competitive markets are in themselves an extraordinary force of innovation, and tend to dissolve the conservative forces that try to keep intact the existing spheres of power. These include economic entities like big corporations (that try to obtain excessive returns from their in- 
vestment thanks to patents and patent laws, for example), but also intellectual monopolies, like 'paradigms', 'schools' or any other type of dominant groups within science (Cf. Boldrin and Levine 2008). Adherence to 'community values' may often be just a rhetorical way to restrain innovation and to hamper the development or transmission of new, revolutionary ideas. Transforming the institutions of science so that less 'orthodox' ideas can flow more freely might serve to discover more quickly the 'anomalies' of the old paradigms. Probably the necessary institutional reforms should not lead to a kind of science as the 'commodified' one castigated by Hasselberg, Mirowski and others, but it's difficult to imagine how could we scrutinize the workings of different alternative scenarios if we are not guided by some economic-like ideas about the rational behaviour of scientists under each possible set of circumstances.

\section{REFERENCES}

Akerlof, George A. 1970. The market for lemons. Quality uncertainty and the market mechanism. Quarterly Journal of Economics. 84/3: 488-500.

Ballandone, Mathieu. 2012. New economics of science, economics of scientific knowledge and sociology of science: The case of Paul David. Journal of Economic Methodology, 19/4: 391-406.

Birchler, Urs, and Monika Bütler. 2007. Information economics. New York: Routledge.

Boldrin, Michele, and David K. Levine. 2008. Against intellectual monopoly. New York: Cambridge University Press.

Chang, Hasok. 2004. Inventing temperature: measurement and scientific progress. Oxford: Oxford University Press.

Coase, Ronald. 1937. The nature of the firm. Economica, 4/16:386-405.

Fanelli, Daniele. 2009. How many scientists fabricate and falsify research? A systematic review and metaanalysis of survey data. PLOS One. 4/5: e5738.

Fernández Pinto, Manuela. 2016. Economics imperialism in social epistemology. Philosophy of the Social Sciences. 46/5: 443-472.

García, José A., Rosa Rodríguez-Sánchez, and Joaquín Fdez-Valdivia. 2017. The game between a biased reviewer and his editor. Science and Engineering Ethics. DOI 10.1007/s1 1948-017-9998-8.

Gintis, Herbert. 2009. The bounds of reason: game theory and the unification of the behavioral sciences. Princeton, New Jersey: Princeton University Press

Gosden, Hugh. 2003. 'Why not give us the full story?' Functions of referees' comments in peer reviews of scientific research papers. Journal of English for Academic Purposes. 2: 87-101.

Hasselberg, Ylva. 2012. Demand or discretion? The market model applied to science and its core values and institutions. Ethics in Science and Environmental Policy. 12: 35-51.

Ioannidis, John P. A. 2005. Why most published research findings are false. PLoS Medicine. 2: e124.

Kitcher, Philip. 1990. The division of cognitive labour. The Journal of Philosophy. 87/1: 5-22.

Knorr-Cetina, Karin. 1981. The manufacture of knowledge. An essay on the constructivist and contextual nature of science. Oxford: Pergamon.

Latour, Bruno. 1987. Science in action. Cambridge, Mass.: Harvard University Press.

Laughlin, Robert. 2008. The crime of reason and the closing of the scientific mind. New York: Basic Books.

Mäki, Uskali. 2009. MISSing the world. Models as isolations and credible surrogate systems. Erkenntnis. 70/1:29-43.

Mallard, Graham. 2015. Bounded rationality and behavioural economics. London: Routledge.

Mirowski, Philip. 2011. Science-Mart: Privatising American Science: Cambridge Mass.: Harvard University Press.

Nature (editorial). 2016. Reality check on reproducibility. May 26, 533: 437. 
Sen, Amartya. 1991. Utility: Ideas and terminology. Economics and Philosophy. 7: 277-283.

Siebert, Sabina, Laura Machesky, and Robert Insall. 2015. Overflow in science and its implications for trust. eLife. 4 (sept 2015): e10825

Weisberg, Michael. 2017. New approaches to the division of cognitive labour. in Paul D. Magnus and Jacob Busch (eds.), New waves in philosophy of science. London: Palgrave Macmillan, forthcoming.

Zamora Bonilla, Jesús. 2011a. The economics of scientific knowledge. In Uskali Mäki (ed.), Handbook of philosophy of economics, 759-798. Elsevier: Amsterdam.

Zamora Bonilla, Jesús. 2011b. Rationality in the social sciences: Bridging the gap. In Ian Jarvie and Jesús Zamora Bonilla (eds.), The SAGE Handbook of the Philosophy of Social Science, 721-738. SAGE: London.

Jesús Zamora Bonilla is full professor of Logic and Philosophy of Science at UNED (Universidad Nacional de Educación a Distancia, Madrid), full member of the Académie Internationale de Philosophie des Sciences, and funding member and member of the steering committee of the European Network of Philosophy of the Social Sciences (ENPOSS). Amongst his recent publications is the essay Sacando consecuencias: una filosofía para el siglo XXI (Tecnos).

AdDREss: Departamento de Lógica, Historia y Filosofía de la Ciencia. Facultad de Filosofía. UNED. Senda del Rey, 7. 28040 Madrid (Spain). Email: jpzb@fsof.uned.es 